\title{
How we could Industrial Working with Minimize Patient Risks in Standard Legal Safety Orthopady Processing in Clinics OECD
}

\author{
Antonín Cuc* \\ Czech Technical University Prague, Mechanical Faculty, Artificial Intelligence, Health and Safety in Medical Devices, Europe
}

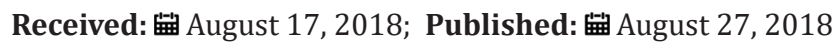

*Corresponding author: Antonín Cuc, Czech Technical University Prague, Mechanical Faculty, Artificial Intelligence, Health and Safety in Medical Devices, Europe

\section{Introduction}

We could in Cybernetics all yearly produce Health care in Orthopady Clinics OECD to describe as parallelly working similar Informal Channels in network OECD, namely with many repeated similar standard processing in preoperative, operative and postoperative similar Health care. It could be realized in the proportional gradual Samplings - when we could defined stratificated clusters of similar Orthopady Clinics with next internal Samplings - for Example of 3\% in proportional Samplings- Patients of sum number of Orthopedic hospitalized Patients in year XXXX, which were for minimize 3 days in Health care in hospital bed - with standard types of realized Orthopedic surgeries - for example Total Hip Arthroplasty, Total Knee Arthroplasty, substitutes of skeletal spinal elements, reoperations of Arthroplasty Hip, Knees, etc.

In Orthopady Clinics OECD we could recognize similar main streams of Stabil Class standard medical repeated main of medical Tasks of cooperated Orthopaeds, Radiologs, Managers, Capacity Planners, Capacity of Departments of Intensive Units Health care, medical activities and medical staff in Surgeon Halls, etc. by usage similar Diagnostics and similar recommending Treatments, similar Medicaments, implementing efficient next modern Mass of Medical Devices, Technical and IT equipment's on the Workplaces with usage praxes by Technical requirements of Laws only, by exact Producer in voids, with usage firm installing instruments, firm radiological masks, measurements the right positions of Orthopadic implants in bones by the same Clinic processing - as there were used in the Tested medical processing in Clinic Tests of each new Medical Devices with finished Approval of rules FDA or by rules CE marking by Conformity Assessment in States EU. Do you ignore the sharing such competent medical elementary deep results in medical processing from Development Phases and Clinic Tests Medical Devices so as in next praxes of Users to forget for more worse fuzzy sharing the origin information from approval Patterns? WHY?
We have similar educated medical and nurse staff by Users, as the certificated Providers Health care with medical staff but with repeated Mass similar medical mistakes in Decision making - in Orthopady Clinics OECD, we could define typical yearly statistic structure of Orthopadic diseases our incoming Orthopadic Patients in comparison years 2016, 2018. 2020 mostly with similar locomotion and neurological additional complicated problems - in similar fixed cases of Clusters Orthopadic Patients, namely by typical important differences of Age, Gender, private personal Weight, skeletal structure with similar deformities, with typical co-incidences with other additional parallelly problems for Medical Decision: namely with frequent high Blood Pressure Patients, with frequent Diabetes Melitus, with often repeated Osteoporoses of bones of Patients over Age 65+, with critical Blood circulation with similar trombotic blood vessel multilateral risks, with often personal Heart Weakness, Heart Arrythmia, problematic Health status after some light Strokes, sometimes with presence of horrible Diagnoses HIV, TBC, Hemorragic Infects, typical polytraumatic Health problems after street Crashes of cars, heavy locomotion injuring after extremal Sport activities or after occupational injuring in dangerous industrial workplaces-namely in Building, Mining, Metallurgy, after critical mental problems after realization of total Anesthesy in Clinic praxes, etc. I never could accept frequent absence of mandatory creating Clinic Plans of daily Surgeries, Orthopady planning, etc.

\section{On First Views of Experts in Cybernetics in Orthopady}

There are lack of cooperative mutual testing and sharing important used the sufficient Mass of Healthy and medical invitable legal information in mutual comparison of parallelly working Orthopady Clinic OECD we prefer the transfer of Best skills only, statistic and forensic multilateral validated sufficient information including: biomechanical, medical, technological, organizational knowledges and skills in continual orthopadic right processing to 
guarance minimize Patient risks for a like hood needless individual Los of private, Well being, namely in next locomotion and mental individual abilities of Patients, with reliable biostatistics prediction to rescue for each of orthopadic Patient - in future Long Safety Lives after standard Orthopadic Treatments in standard acceptable legal Technical and Medical Quality of finished Medical Processing in Assurance financial acceptable summary limits, in respects to continual next growing level of multilateral Medical Knowledges in Orthopady branche, with regards to increases of better Quality of used World sophisticated Medical Devices in common Market, with we supposed the continual independent regularly testing resulting quality of the yearly Produce Health care in each Orthopady Clinics OECD, for example by independent continual proportional Samplings with support Artificial Intelligence to evaluating Clusters of Patients, with modelling of locomotion preliminary and reliable planning post operational individual abilities of Patients in defined Clusters, with regularly scanning preliminary and post operational bones in Geometry 3D including placement of implants for Clinic Plans, with intensive usage Artificial Intelligence in controlling perfect anchoring post operational biomechanical functional placement of implants, with regularly realization mutual comparison Cohorts with statistic samplings through and querry with similar Orthopady Clinics in network OECD, etc.

There are yearly realized in Czech Republic about 13 thousand first THA, but there are yearly about 680 orthopadic Patients needless illegal heavy injuring under legally acceptable Technical and Medical Qualities by independent supervisions of my decision method S_T_A_R_S, with casual most illegal crippled and preliminary casual illegal dying Patients CZ many years earlier! None of the Orthopadic Clinic CZ has enough Courage to cooperate with me and stopped such yearly repeated Tragedies! They woéuld like to continue in petrification false medical workflow so as after me in forced needless illegal Death. The Czech Professors of Orthopady are smiling to my opened published Criminal evidence of casual medical mistakes by my Surgeon Total Hip Arthroplasty since November 13, 2007 - in aspects Biomechanics, in Geometry 3D, in Criminal Radiology - there are namely illegal placement the spice Stem in coordinates Xi, Yi, Zi by Fausse ropute stem contrary Radiology firm legal Radiologic installing Patterns from the firm B. Braun Germany in all post operational RTG images since November 16, 2007, since November 28, 2007 in Regional Hospital Mladá Boleslav CZ, despite I am just dying needless too. The constant Glorification of Mass orthopadic repeated Mass stupidities MADE CZ in medical workflow CZ - It is legal and World multilateral scientific Criminal scandal!

In Czech Republic there are just namely usual and Well funny to kill the State investigator of occupational mortalities from the Ministry of Labor and Social Affairs CZ with false arguments there are Fausse route stem since November 13, 2007 as a typical Patient Orthopady Post operational Risks in Limits Lege Artis CZ. UNBELIEVE BETRAYAL OF HUMANISTIC MEDICINE OECD !
There are possible to implement the similar organizational legal procedural fixed technical controlled conditions, as we are known risks in details for Ages from the network of Producer Airplaines, produce of Cosmic Rackets, continual produce Energy in Nuclear power stations, produce of Computers, managing continual activities of international functional Airports for all coming and leaving Passengers-Clients, with actual timing need certificated Repearing services and testing of all used Airplaines, competent responsible Healthy and Competency of Pilots, continual regularly Air conditions testing for safety landing, legal conditions for coming safety each Clients into Airplaines with excluding risk of next probable terroristic Explosures, etc.

Professors of Orthopady CZ are smiling me till my Death as a famous Innovator in Health care, but I don't. They would namely petrificated the false medical orthopadic workflow for ever without a like hood responsibilities Legalities of parallelly working Providers Health care and Medical Staff CZ! Since 1976 it was a background in multilateral scientific knowledges for my inspiration to develop Decision Method S_T_A_R_S Statistical Retrieval and Search of enough information to reuse for similar Mass repeated strategic decision with risk and computer support, see the Utility model 21532 CZ since 2010.

We could namely to sharing the best Patterns-detailed structural Medical Orthopadic processing in parallelly working orthopadic Channels, with guarancy step by step - to exclude repeating all known fatal medical mistakes in time in all repeated standard Orthopady medical processing with standard dangerous certificated Medical Devices, with standard sufficient tested education and well exercised each medical staff of Users in Orthopady Clinic, always with well-informed Orthopadic Patients with their qualificated judicial agreements with next medical procedures, continual independent supervision over parallelly working Orthopady in network OECD with usage statistic validated orthopadic Patterns including reglement approval Electronic Health well-structured Patient Records-and including shared processing Video records of standard protocolled Surgeries-Patterns, Orthopadic verified Protocols in surgeon Hall with commentary of Producers orthopadic Implants, with creating of common, Sharing Orthopadic International processing Pattern books for each typical works in orthopadic User Clusters, namely with standard surgeon sequential in forced controlled activities including each individual reliable Clinic Plans of each surgeries by computerized supervisions, etc.

Yes, I am just needless dying Orthopadic Patient CZ after fatal changed many medical partial illegal activities in standard Orthopadic classic Surgeon TOTAL HIP ARTHROPLASTY, despite the culprits-namely Orthopaeds CZ, Radiologs CZ, Czech Medical Knowing Institutes, Justice CZ-till my Death they were repeated false biomechanical judicial results: Patient Unhappy in limits legal working medical staff-Lege Artis CZ. But, similar ways with smiling of Professors in Orthopady without controlling the mandatory existence of individual Clinics Plan - there are yearly in Czech 
Republic needless illegal crippled and preliminary dying for illegal usage standard Medical Devices about 40 thousand Patients CZ, all false classified Patient Unhappy, by medical staff were while times always working Lege Artis CZ only! (Figures 1 \& 2).

\section{SARS Statistical Retrieval and Search information for decision making JIARS statistické vyhledáni a znovuužiti informace k rozhodování}

\section{(C) Ing. Antonín Cuc, Praha 1976 \\ Chránēno jako Użtný průmyslový vzor ČR od roku 2010}

\section{Consequents discovery S_T_A_R_S}

as a new cybernetic model to concatenation of sequential decision making

Every innovation could be evaluated with high probability as a statistical multicriterial hypothesis about significant differences in estimates of important statistical parameters of existing and future in a Transformal Channel, with regards to a reasonable actual level of statistical reliability and accuracy of strategic decision-making of purpose and destination of the transformation behavior of the channel with recognizing its internal and external risks and considering its likely long-term existence in interaction with significant surroundings.

It could be used to take priorities in choice of variants innovations.

All transformation processes in managing so as in managed processing should be continuously provided subject to continuous minimize summ increases of entropy.

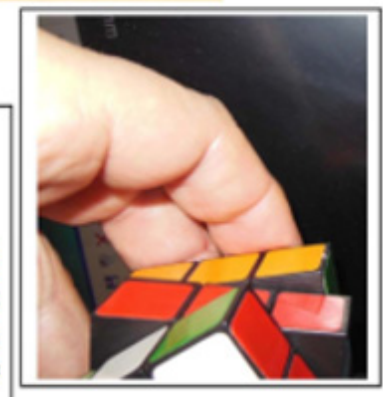

Figure 1.

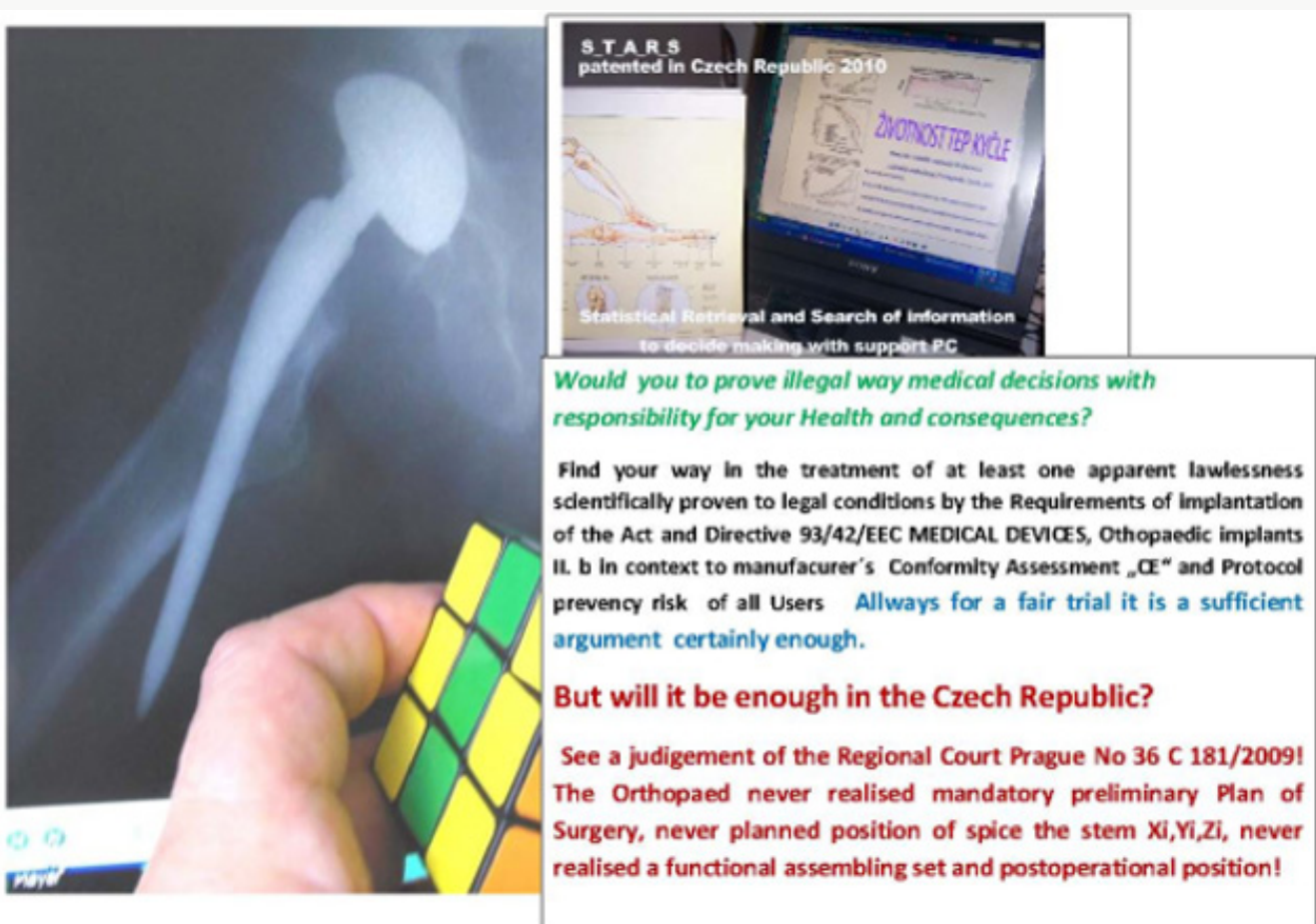

Figure 2.

This is a secret civic petrificated continual war of bad educated Physicians CZ in Biomechanics, Geometry 3D, Criminal Logics against other Citizens CZ- Patients CZ in network Hospitals CZ with similar Mass of preliminary needless casual dying Victims
CZ, contrary Technician requirements of Laws, contrary Criminal Logics, contrary Criminal material tracing and evidences false Kinematic trajectories in Geometry 3D, contrary Constitutional Human rights CZ to Health care always in limits Technician 
requirements of international Laws for each safety processing used Medical Devices, contrary todays habits to take Health care CZ out of guaranteed legal limits medical processing by rules. Based Evidenced Medicine including respects to fixed Technical processing conditions Directive 93/42/EEC Medical Devices, certification of Users, medical staff, Firm product in voids with approval, CE, FDA, etc.

At least being the One partial illegal medical activity always it is deriving resulting whole content as resulting by Binary Logics without any doubts with evaluating-Illegal finished Medical Processing definitely! Nobody from Professors Orthopady CZ could immediately change the horrible Mass repeated medical orthopadic partial illegal processing mistakes with de-evaluating most part of yearly finished Medical Processing CZ with Mass repeated criminal evidences contrary Logics, Cybernetics and Biomechanics CZ, Technical Requirements of Laws for legal usage Medical Devices. We are producing Crippled Patients CZ!? I am a solitaire needless dying Scientist CZ, like as official hated scientist Giordano Bruno in year 1599. Justice CZ and Criminal Police CZ hate me very sincerely.

That's for my casual in forced orthopadic and leukemic individual Patient Death is a collective wisdom Medical Mord CZ of the Scientist in Cybernetics-with constant duration repeated full false casual official agreements of Justice CZ, so as false argumentation from The Criminal Police CZ, so as with placement the false medical hypoheses in Court medical Message from The Medical Knowing Institute CZ - The Central Army Hospital Prague, CZ till todays. It is my needless horrible public official slowly Execution CZ, see the Regional case Court of Prague CZ and Court Medical Message, No. 36 C 181/2009-123 since March 27, 2012 and the derived Judgement No. 36 C 181/2009-221 since September 24, 2012 - I crippled the punctuare Crash, Fausse route stem in surgeon hall since November 13, 2007 as a post operational Patient Fall?! It could say only my Murders!

May be US Orthopady could be cleverer in cooperation with me or in individual next US Orthopadic Research by respects to principles Method S_T_A_R_S, Utility Model 21532 CZ 2010 for industrial continual testing by Samplings, namely all yearly Produce Health care in all Orthopady Clinics OECD with mutual parallelly statistic comparison multilateral legal Technical and Medical, Processing Qualities, Safety, Efficiency!

\section{The used and Contextual Literature}

a) Antonín Cuc: Utility model 21532 CZ 2010, The Equipment for Retrieval and Search of sufficient information to reuse for Mass repeated similar strategic decision making with risk and computer support, Czech Office for Industrial law, Prague, CZ.

b) The Directive 93/42/EEC Medical Devices, harmonized Laws EU/CZ since 2004.

c) Input Health Orthopadic Documentation of Plaintiff Antonín Cuc for judicial case of Regional Court Prague, CZ, set RTG of post operational Images, including protest letter of the Plaintiff since July 17, 2012 for hands Judge JU Dr. Vojtěch Cepl with parallelly sent letters to the Director of The Regional Hospital Mladá Boleslav CZ MU Dr. Jiří Med, so as to hands of the Head of Team of forensic doctors The Central Army Hospital Prague CZ - prime MU Dr. Miloš Sokol, Department of forensic Medicine - all it was copied in the personal Linkedin sides Antonín Cuc, with full declared official biomechanical false argumented medical Hypotheses in The Court Medical Message No. 36 C 181/2009-123 since March 27, 2012 with false criminal bio mechanic argumented the Judgement No. 36 C 181/2009-221 since September 24, 2012.
This work is licensed under Creative Commons Attribution 4.0 License

To Submit Your Article Click Here: Submit Article

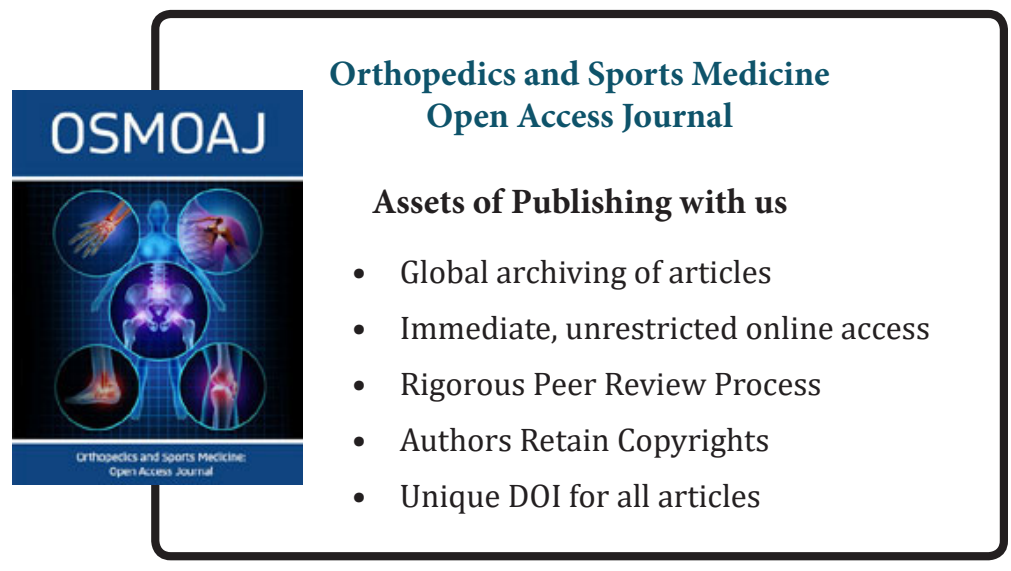

